\title{
Stress and substance use among undergraduate medical students in a Government medical college in Northern Karnataka
}

\author{
Shivanand B Hiremath ${ }^{1, *}$, V H M Chaitra ${ }^{2}$, Desai Mahesh ${ }^{3}$ \\ ${ }^{1}$ Senior Resident, ${ }^{2}$ Psychiatrist, ${ }^{3}$ Professor and Head, ${ }^{\mathbf{1} 3}$ Dept.of Psychiatry, Karnataka Institute of Medical Sciences, Hubli, Karnataka, \\ ${ }^{2}$ Aantharya Neuropsychiatric Centre, Hubli, Karnataka, India \\ *Corresponding Author: Shivanand B Hiremath \\ Email: bhshiv@gmail.com
}

\begin{abstract}
Context: Medical education is highly stressful and demanding as a career. Although, only the academically-minded youth in the society tend to be selected for medical education, the stressful academic environment can exert a negative effect on the psychological and physical well-being. There is growing concern about substance use/dependence among medical students. While medical students and doctors help patients resolve substance dependency, they are not immune to these temptations themselves. In addition to negative effects on the individual's physical and mental health, and on their families, substance abuse may threaten the ability to provide adequate patient care, and it may undermine the individual's role as a role model for healthy lifestyles.

Aims: To assess the stress and substance use and association among them among undergraduate medical students.

Settings and Design: It was a cross sectional study with second, third and final year undergraduate medical students of a government medical college in Northern Karnataka as subjects.

Materials and Methods: Basic demographical data was collected using a semi structured questionnaire, substance use was assessed using WHO ASSIST 3.0 scale, stress was assessed using Medical Student Stressor Scale (MSSQ).

Statistical analysis used: Data was compiled and appropriate statistical tests were used to analyse the data with the help of SPSS 20.

Results: Out of 450 second, third and final year undergraduate medical students, 403 participated in the study. The prevalence of substance use was about $34.7 \%$ with alcohol being the leading substance followed by marijuana. Few students reported inhalant/volatile substance use. $65 \%$ of the subjects reported high stress. Stress was almost equal in almost all domains.

Conclusions: Effective interventions have to be planned and implemented to reduce stress levels among medical students and to address the issue substance use by promoting healthy life style and coping skills.

Key Messages: There is association between stress and substance use among undergraduate medical students. Effective interventions have to be planned and implemented to reduce stress levels among medical students and to address the issue substance use by promoting healthy life style and coping skills.
\end{abstract}

Keywords: Medical students, Stress, Substance use.

\section{Introduction}

In a developing country like India, historically and culturally, medical profession is considered as one of the highly respected professions. It is a great dream for many of the pre university students to get into medical course. ${ }^{1}$ But medical education is highly stressful and demanding as a career. Academic pressure producing stress in a student is not surprising, but this is not the only source of stress among them. ${ }^{2}$ Many other factors namely the teaching style, inter and intrapersonal issues, drive and motivation related problems and social reasons may also contribute to the distressed state of the learner. In addition to stress, the students' social, emotional and physical as well as family problems may influence their learning ability and academic performance. ${ }^{3}$ Previous studies have shown fairly high levels of distress, such as symptoms of depression ${ }^{4,5}$ and suicide thoughts ${ }^{6-7}$ among medical undergraduates. The potential negative effects of emotional distress on medical students include impairment of functioning in class-room performance, clinical practice and impaired mental health. ${ }^{8-9}$ Higher levels of stress may have a negative impact on the students learning ability. Excessive stress may result in mental and physical problems and may diminish a student's sense of worth and might affect his/her academic achievement. ${ }^{10,11}$
Studies from west, that have examined coping strategies of medical students with the stresses of undergraduate medical education have generally identified, use of alcohol as a coping strategy $y^{12-14}$ but some studies have reported the use of other substances such as tobacco and drugs. ${ }^{15,16}$ Studies from developing countries like Pakistan, India, Thailand and Malaysia have reported stress among medical students and have underscored the role of academics as a source of stress. ${ }^{1,17,18}$

Stress may affect health by producing changes in behaviour and there is evidence that under high levels of stress, health-enhancing behaviour declines and healththreatening behaviour such as consumption of tobacco, alcohol, and other drugs may increase, so people are more likely to engage in behaviours that increase the risk of illness and injury. ${ }^{19}$ There is considerable evidence from population-based and clinical studies supporting a positive association between psychosocial adversity, negative affect, and chronic distress and addiction vulnerability. Previous studies $^{20-22}$ have estimated a prevalence rate of substance abuse to be around 20-40 per cent among undergraduate medical students.

So, the present study assesses the prevalence of stress and substance use among undergraduate medical students and association between them. 


\section{Materials and Methods}

A cross-sectional study was conducted among medical undergraduate students in a government medical college in Karnataka between June and July 2017 to assess the prevalence of stress and substance use among undergraduate medical students and association between them.

A total of 450 bachelor of medicine and bachelor of surgery (MBBS) students from second year to final year were studying in the institute. Institutional ethical committed permitted to conduct the study. All the undergraduate medical students from second year to final year MBBS were invited to participate in the study. The purpose of the study was explained to the participants, and a written informed consent was obtained during their theory class. The students who consented to participate in the study were included and were asked to complete a selfadministered pre structured anonymous questionnaire consisting of the following sections: (a) sociodemographic profile (b) medical students' stressor questionnaire (MSSQ$40)^{23}$ (c) World Health Organization Alcohol, Smoking and Substance Involvement Screening Test v 3.0. (WHO ASSIST v 3.0). ${ }^{24}$ They were given 50 minutes to complete the questionnaire and asked to put the questionnaire in a ballot box kind of set up in a predesignated place in the class room and their roll numbers were noted separately for their class attendance as well as to note down the absentees. Those who were absent in the class were later invited to be a part of the study. Data was compiled and appropriate statistical tests were used to analyze the data with the help of SPSS 20.

\section{MSSQ-40 ${ }^{23}$}

The MSSQ-40 is a rating tool developed in a medical institute in Malaysia and validated to measure stress and its sources among medical students. It assesses six domains of sources of stress namely academic-related stressors (ARS), intrapersonal and interpersonal-related stressors (IRS), teaching and learning-related stressors (TLRS), social-related stressors (SRS), drive and desire related stressors (DRS) and group activities related stressors(GRS). Participants are asked to respond to each item along a five point Likert scale (0-4), zero being no stress at all to four being severe stress. The scoring was done as per the instructions of the scale and the stress levels were graded as mild $(<1)$, moderate (1.01-2), high (2.01-3), and severe (>3). The mean score obtained reflects on the overall stress status of the participant. Mild stress indicates a near absence of stress while moderate shows the ability of the student to manage well. High score shows that emotions maybe labile whereas severe stress indicates the difficulty in coping with day to day activities.

\section{The Alcohol, Smoking and Substance Involvement Screening Test (ASSIST) v 3.0 ${ }^{24}$}

It was developed under the auspices of the World Health Organization (WHO) to be used in primary health care settings where hazardous and harmful substance use among clients may go undetected, or become worse. The ASSIST (version 3.0) is an eight item questionnaire designed to be administered by a health care professional to a client, and takes about five to ten minutes to administer. The ASSIST was designed to be culturally neutral and useable across a variety of cultures to screen for use of the following substances: tobacco products, alcohol, cannabis, cocaine, amphetamine-type stimulants, inhalants, sedatives and sleeping pills (benzodiazepines), hallucinogens and 'other' drugs.

The ASSIST determines a risk score for each substance. It obtains information from clients about lifetime use of substances, and use of substances and associated problems over the last three months. Scores in the mid-range on the ASSIST are likely to indicate hazardous or harmful substance use ('moderate risk') and higher scores are likely to indicate substance dependence ('high risk').

\section{Results}

Out of 450 students, 403 responded with response rate being $89.5 \%$. As seen in Table 1, among the respondents, 225 $(55.8 \%)$ were males and $178(44.2 \%)$ were females. 147 $(36.5 \%)$ students were studying in second year, 131 (32.5\%) were in third year and $125(31 \%)$ in final year MBBS. 320 (79.4\%) were Hindu, 49(12.2\%) were Muslims, 27(6.7\%) were Christians. 328(81.4\%) stayed in hostel, 52 (12.9\%) stayed at home, $12(3 \%)$ stayed with their relatives and 11 $(2.7 \%)$ stayed as paying guests.

In the study, on MSSQ, scores of more than 1.01 were considered as having stress. $246(61.1 \%)$ students, had collective score of $>1.01$ signifying stress among majority. As seen in table 2, among various stress domains, stress was high in academic related (78.4\%), interpersonal and intrapersonal (70\%) and group activity related (68.7\%) domains. Drive and desire related domain had least stress $(39.5 \%)$.

There was significant association $(\mathrm{p}<0.05)$ between the year of MBBS and stress. As the year of study progressed, the stress also increased, especially in the academic related domain.

While assessing substance use, 140 (34.7\%) students reported use of either one of tobacco, alcohol, cannabis, cocaine, inhalants, sedatives, hallucinogens, and opioids at least once in their lifetime. Prevalence of substance use increased as the year of MBBS progressed.(Table 3)

Among the respondents, $49(12.6 \%)$ were at moderate to high risk for tobacco use, $40(9.9 \%)$ for alcohol, 29 (7.2\%) for cannabis, 14 (3.4\%) for inhalants, and $11(2.6 \%)$ for sedatives. (Table 4)

The association of academic related stress was significant $(\mathrm{p}<0.05)$ with tobacco, alcohol, cannabis, inhalants and sedatives use (Table 5). Similarly, inter and intrapersonal, teaching and social related stress was significantly associated with tobacco, alcohol, cannabis and inhalants use. Drive and desire and group activity related stress was significantly associated with tobacco, alcohol and cannabis use. 
There was no significant association of stress with gender, religion and place of stay. There was also no significant association between substance use and gender, religion and place of stay.

Table 1: Socio-demographical details

\begin{tabular}{|l|l|c|}
\hline \multirow{3}{*}{ Gender } & & $\mathbf{N}(\mathbf{\%})$ \\
\hline \multirow{5}{*}{ Year of MBBS } & Male & $225(55.84 \%)$ \\
\cline { 2 - 3 } & Female & $178(44.16 \%)$ \\
\cline { 2 - 3 } & Second & $147(36.48 \%)$ \\
\cline { 2 - 3 } & Third & $131(32.5 \%)$ \\
\cline { 2 - 3 } & Final & $125(31.01 \%)$ \\
\cline { 2 - 3 } & Hostel & $328(81.4 \%)$ \\
\cline { 2 - 3 } & Reme & $52(12.9 \%)$ \\
\cline { 2 - 3 } & Relative & $12(3 \%)$ \\
\cline { 2 - 3 } & Paying guest & $11(2.7 \%)$ \\
\hline \multirow{5}{*}{ Religion } & $18-20$ & $182(45.2 \%)$ \\
\cline { 2 - 3 } & $21-23$ & $214(53.1 \%)$ \\
\cline { 2 - 3 } & $>24$ & $7(1.7 \%)$ \\
\cline { 2 - 3 } & Hindu & $320(79.4 \%)$ \\
\cline { 2 - 3 } & Muslim & $49(12.2 \%)$ \\
\cline { 2 - 3 } & Christian & $27(6.7 \%)$ \\
\cline { 2 - 3 } & Jain & $4(1 \%)$ \\
\cline { 2 - 3 } & Others & $3(0.7 \%)$ \\
\hline
\end{tabular}

Table 2: MSSQ stress domains and their respective scores

\begin{tabular}{|l|c|c|}
\hline \multirow{2}{*}{ MSSQ* Stress Domains } & \multicolumn{2}{|c|}{ MSSQ Scores from 1.01-4.00 } \\
\cline { 2 - 3 } & $\mathbf{N ~ ( 4 0 3 )}$ & $\mathbf{\%}$ \\
\hline Academic Related & 316 & $78.4 \%$ \\
\hline Interpersonal and Intrapersonal related & 282 & $70 \%$ \\
\hline Teaching and Learning related & 222 & $56.1 \%$ \\
\hline Social Related & 222 & $56.1 \%$ \\
\hline Drive and desire related & 159 & $39.5 \%$ \\
\hline Group Activity related & 277 & $68.7 \%$ \\
\hline
\end{tabular}

* Medical Student stressor questionnaire

Table 3: Relationship of substance use with gender and year of study

\begin{tabular}{|l|c|c|c|}
\hline \multirow{2}{*}{} & \multicolumn{2}{|c|}{ Substance Use } & \multirow{2}{*}{ P } \\
\cline { 2 - 3 } & Yes & No & \multirow{2}{*}{$>0.05$} \\
\hline Male & $87(38.66 \%)$ & $138(61.34 \%)$ & \\
\hline Female & $53(29.78 \%)$ & $125(70.22 \%)$ & \multirow{2}{*}{$<0.05$} \\
\hline $2^{\text {nd }}$ Year & $40(27.21 \%)$ & $107(72.79 \%)$ & \multirow{2}{*}{$<0.05(67.18 \%)$} \\
\hline $3^{\text {rd }}$ Year & $43(32.82 \%)$ & $68(54.4 \%)$ & \\
\hline Final Year & $57(45.6 \%)$ & $263(65.27 \%)$ & \\
\hline & $140(34.73 \%)$ & & \\
\hline
\end{tabular}

Table 4: Risk of various substances of use

\begin{tabular}{|l|c|c|c|c|c|c|}
\hline \multirow{2}{*}{ Substance } & \multicolumn{2}{c|}{ Low Risk } & \multicolumn{2}{c|}{ Moderate Risk } & \multicolumn{2}{c|}{ High Risk } \\
\cline { 2 - 7 } & Count & $\mathbf{\%}$ & Count & \% & Count & \% \\
\hline Tobacco & 352 & $87.3 \%$ & 42 & $10.4 \%$ & 9 & $2.2 \%$ \\
\hline Alcohol & 363 & $90.1 \%$ & 33 & $8.2 \%$ & 7 & $1.7 \%$ \\
\hline Cannabis & 374 & $92.8 \%$ & 26 & $6.5 \%$ & 3 & $0.7 \%$ \\
\hline Cocaine & 403 & $100.0 \%$ & 0 & $0.0 \%$ & 0 & $0.0 \%$ \\
\hline Amphetamine & 402 & $99.8 \%$ & 1 & $0.2 \%$ & 0 & $0.0 \%$ \\
\hline Inhalants & 389 & $96.5 \%$ & 13 & $3.2 \%$ & 1 & $0.2 \%$ \\
\hline Sedatives & 392 & $97.3 \%$ & 10 & $2.5 \%$ & 1 & $0.2 \%$ \\
\hline Hallucinogens & 402 & $99.8 \%$ & 1 & $0.2 \%$ & 0 & $0.0 \%$ \\
\hline Opioids & 401 & $99.5 \%$ & 2 & $0.5 \%$ & 0 & $0.0 \%$ \\
\hline Others & 403 & $100.0 \%$ & 0 & $0.0 \%$ & 0 & $0.0 \%$ \\
\hline
\end{tabular}


Table 5: Association of various domains of stress with substance use

\begin{tabular}{|c|c|c|c|c|c|c|c|c|c|c|}
\hline \multirow{2}{*}{\multicolumn{2}{|c|}{ Risk }} & \multicolumn{8}{|c|}{ Academic Related } & \multirow[t]{3}{*}{ P value } \\
\hline & & \multicolumn{2}{|c|}{ Mild Stress } & \multicolumn{2}{|c|}{ Moderate Stress } & \multicolumn{2}{|c|}{ Severe Stress } & \multicolumn{2}{|c|}{ Very Severe Stress } & \\
\hline & & Count & $\%$ & Count & $\%$ & Count & $\%$ & Count & $\%$ & \\
\hline \multirow{3}{*}{ Tobacco } & Low & 84 & $23.9 \%$ & 160 & $45.5 \%$ & 92 & $26.1 \%$ & 16 & $4.5 \%$ & \multirow[t]{3}{*}{$<0.001^{*}$} \\
\hline & Moderate & 1 & $2.4 \%$ & 6 & $14.3 \%$ & 19 & $45.2 \%$ & 16 & $38.1 \%$ & \\
\hline & \begin{tabular}{|l} 
High \\
\end{tabular} & 2 & $22.2 \%$ & 2 & $22.2 \%$ & 2 & $22.2 \%$ & 3 & $33.3 \%$ & \\
\hline \multirow{3}{*}{ Alcohol } & Low & 86 & $23.7 \%$ & 163 & $44.9 \%$ & 98 & $27.0 \%$ & 16 & $4.4 \%$ & \multirow[t]{3}{*}{$<0.001^{*}$} \\
\hline & Moderate & 1 & $3.0 \%$ & 4 & $12.1 \%$ & 13 & $39.4 \%$ & 15 & $45.5 \%$ & \\
\hline & High & 0 & $0.0 \%$ & 1 & $14.3 \%$ & 2 & $28.6 \%$ & 4 & $57.1 \%$ & \\
\hline \multirow{3}{*}{ Cannabis } & Low & 85 & $22.7 \%$ & 165 & $44.1 \%$ & 103 & $27.5 \%$ & 21 & $5.6 \%$ & \multirow[t]{3}{*}{$<0.001^{*}$} \\
\hline & Moderate & 2 & $7.7 \%$ & 3 & $11.5 \%$ & 9 & $34.6 \%$ & 12 & $46.2 \%$ & \\
\hline & \begin{tabular}{|l|} 
High \\
\end{tabular} & 0 & $0.0 \%$ & 0 & $0.0 \%$ & 1 & $33.3 \%$ & 2 & $66.7 \%$ & \\
\hline \multirow{3}{*}{ Inhalants } & Low & 86 & $22.1 \%$ & 165 & $42.4 \%$ & 107 & $27.5 \%$ & 31 & $8.0 \%$ & \multirow[t]{3}{*}{$0.043^{*}$} \\
\hline & Moderate & 1 & $7.7 \%$ & 3 & $23.1 \%$ & 5 & $38.5 \%$ & 4 & $30.8 \%$ & \\
\hline & High & 0 & $0.0 \%$ & 0 & $0.0 \%$ & 1 & $100.0 \%$ & 0 & $0.0 \%$ & \\
\hline \multirow{3}{*}{ Sedatives } & Low & 87 & $22.2 \%$ & 164 & $41.8 \%$ & 111 & $28.3 \%$ & 30 & $7.7 \%$ & \multirow[t]{3}{*}{$<0.001^{*}$} \\
\hline & Moderate & 0 & $0.0 \%$ & 4 & $40.0 \%$ & 1 & $10.0 \%$ & 5 & $50.0 \%$ & \\
\hline & High & 0 & $0.0 \%$ & 0 & $0.0 \%$ & 1 & $100.0 \%$ & 0 & $0.0 \%$ & \\
\hline
\end{tabular}

\section{Discussion}

The prevalence of stress among undergraduate medical students in our study was $61.1 \%$, which is almost similar to the prevalence reported by previous studies. ${ }^{25-29}$ However, Studies investigating stress among Indian medical students report wide variations in the prevalence of stress (37.397\%). ${ }^{30-34}$ This observed inconsistency can be explained by demographic differences in the samples, different academic years of the students studied, varying case definitions, and no uniformity in measuring tools. ${ }^{31}$ The possible reasons for the variability in the levels of stress could be due to certain differences in the curricula, teaching facilities, qualification and experience of the instructors, and the levels of care given to the students. Academic counselling is not a common practice in the present setup because of a large number of medical students and limited number of the faculties that may contribute to high prevalence of stress. ${ }^{31}$

Our subjects experienced more stress in academic related domain. In most of the previous studies, students reported similar academic related stress. ${ }^{31}$ Few of the issues in which they were stressed were - tests /exams, selfexpectation, heavy workload, not enough skills, full of competition, having difficulty in understanding the content, getting poor marks, lack of time for revision, large syllabus to learn and unjustified grading system. Medical students are overloaded with a tremendous amount of information. The excessive amount of stress in medical training predisposes students to have difficulties in solving problems and reduced concentration and finally develop depression. ${ }^{26}$ Furthermore, stress among medical students can break the mental stability, impaired judgments, and absenteeism from class lesson. In effect, all those things compromise academic achievement of students. ${ }^{25}$

As the students progressed to higher classes in medical course the amount stress increased. This can be attributed to high volume of study material, expectation and increased competition. ${ }^{21} \mathrm{~A}$ high prevalence of stress among medical students is a cause of concern as it may impair behaviour of students, diminish learning, and ultimately affect patient care after their graduation. ${ }^{35,36}$

In our study, $34.7 \%$ of the subjects had used either one of tobacco, alcohol, cannabis, cocaine, inhalants, sedatives, hallucinogens, and opioids at least once in their lifetime. The result was the in the range of prevalence of substance use seen among undergraduate medical students in the previous studies. $^{37-40}$

There was significant association between year of study and substance use. As the year of study advanced, prevalence of substance use also increased. This may be attributed to increased syllabus, clinical postings and exams and increased self- expectation. ${ }^{40}$

Most common substance of use was alcohol followed by tobacco and cannabis. In few other studies tobacco was the most common substance of use. ${ }^{40,41}$

Interesting finding in our study was moderate to high risk of inhalant use in $3.4 \%$ of the subjects. In India Inhalant use is reported among school students and children belonging to lower socioeconomic strata. ${ }^{42}$ But studies among medical undergraduate students don't mention inhalant abuse. But few studies from Greece and Brazil ${ }^{43,44}$ do mention about inhalant abuse with prevalence being $3.1 \%-31 \%$. As inhalants are not contraband and easily available, the usage of this substance is worrisome. This finding needs to be further investigated.

There was also no significant association between substance use and gender, religion and place of stay. It needs more structured and large scale studies to assess the relation between these factors.

Though our study did not assess the reasons for substance us, according to previous studies socialization, feeling of having grown up and relieving from tensions ${ }^{41}$ to relieve of the stress and curiosity, academic stress, peer pressure, failure in love matters also accounted for initiation of substance use among majority of abusers. ${ }^{40-43}$ 
The association of academic related stress was significant $(\mathrm{p}<0.05)$ with tobacco, alcohol, cannabis, inhalants and sedatives use. Similarly, inter and intrapersonal, teaching and social related stress was significantly associated with tobacco, alcohol, cannabis and inhalant use. Drive and desire and group activity related stress was significantly associated with tobacco, alcohol and cannabis use. These findings were similar to findings in the previous studies. ${ }^{20-22}$ The previous studies haven't studied in detail about each substance of use and each domain of stress. But the specific association between type of stress and certain substances abuse needs to be investigated further.

\section{Conclusion}

Stress levels are very high among undergraduate medical students. Substance use is one of the coping mechanisms among them due to high level of stress. So, healthy management of stress is essential among undergraduate medical students.

\section{Limitations}

1. First year MBBS students were not involved in the study and all the participants belonged to one institute. So the results cannot be generalized.

2. The involved self-administered questionnaire so possibility of information bias cannot be ruled out.

3. This was a cross-sectional study, so cause-effect relationships could not be established. Some students might have over- or under-reported their stress and stressful factors.

4. Prospective studies are necessary to study the associations between occurrence of stressors and incidence of stress.

\section{Source of Funding}

None.

\section{Conflicts of Interest}

None.

\section{Acknowledgement}

1. Ms. Aishwarya, Mr. Omar, Ms. Varshita, Mr. Nazim and Mr. Kiran assisting in data collection.

2. Dr. Mahesh V. Assistant professor of Community medicine, for helping us in statistical analysis.

\section{References}

1. Edwards S, Ali R, Poznyak V, Monteiro M. The Alcohol, Smoking and Substance Involvement Screening Test (ASSIST) Manual for use in primary care.3. Newyork: World Health Organization; 2010.

2. Eva EO, Islam MZ, Mosaddek ASM, Rahman MF, Rozario RJ, Iftekhar MH et.al . Prevalence of stress among medical students: a comparative study between public and private medical schools in Bangladesh. BMC Res Note 2015;8:327.

3. Vitaliano PP, Maiuro RD, Mitchell E, Russo J.Perceived stress in medical school: Resistors, persistors, adaptors and maladaptors. Soc Sci Med. 1989;28(12):1321-9.
4. Abdulghani HM, AlKanhal AA, Mahmoud ES,

Ponnamperuma GG, Alfaris EA. Stress and Its Effects on Medical Students: A Cross-sectional Study at a College of Medicine in Saudi Arabia. J Health Supe AN. A study of stress in medical students at Seth G.S. Medical College. J Postgrad Med. 1998;44(1):1-6.

5. Yusoff MSB, Abdul Rahim AF, Baba AA, Ismail SB, Mat Pa $\mathrm{MM}$, Esa AR et al. Prevalence and associated factors of stress, anxiety and depression among prospective medical students. Asian J Psychiatr. 2013;6(2):128-33.

6. Shah M, Hasan S, Malik S, Sreeramareddy CT. Perceived Stress, Sources and Severity of Stress among medical undergraduates in a Pakistani Medical School. BMC Med Educ 2010;10(2):2-8.

7. Dahlin M, Joneborg N, Runeson B. Stress and depression among medical students: a cross sectional study. Med Educ. 2005;39:594-604.

8. Zocolillo M, Murphy GE, Wetzel RD: Depression among medical students. J Affect Disord. 1986;11(1):91-6.

9. Tyssen R, Vaglum P, Gronvold NT, Ekeberg O. Suicide ideation among medical students and youth physicians: a nationwide and prospective of prevalence and predictors. $J$ Affect Disord. 2001;64(1):69-79.

10. Tyssen R, Hem E, Vaglum P, Gronvold NT, Ekeberg O. The process of suicidal planning among medical doctors: predictors in a longitudinal Norwegian sample. J Affect Disord. 2004;80(23):191-8.

11. Malathi A, Damodaran A. Stress due to exams in medical students-role of yoga. Indian J Physiol Pharmacol 1999;43(2):218-24.

12. Bramness JA, Fixdal TC, Vaglum P. Effect of medical school stress on the mental health of medical students in early and late clinical curriculum. Acta Psychiastr Scand. 1991;84(4):340-5.

13. Silver HK, Glicken AD. Medical student abuse. Incidence, severity, and significance. JAMA.1990;263(4):527-32.

14. Niemi PM, Vainiomaki PT. Medical students' academic distress, coping and achievement strategies during the preclinical years. Teach Learn Med. 1999;11(2):125-34.

15. Guthrie EA, Black D, Shaw CM, Hamilton J, Creed FH, Tomenson B et al. Embarking upon a medical career: psychological morbidity in first year medical students. Med Educ. 1995;29(5):337-41.

16. Firth J: Levels and sources of stress in medical students. BMJ(Clin Res Ed). 1986;292(6529):1177-80.

17. Guthrie E, Black D, Bagalkote H, Shaw C, Campbell M, Creed F et al. Psychological stress and burnout in medical students: a 5 -year prospective longitudinal study. J Roy Soc Med. 1998;91(5):237-43.

18. Miller P, Surtees PG. Psychological symptoms and their course in first year medical students as assessed by the Interval General Health Questionnaire (I-GHQ). Br J Psychiatry.1991;159:199-207.

19. Ashton CH, Kamali F. Personality, lifestyles, alcohol and drug consumption in a sample of British medical students. Med Educ.1995;29(3):187-92.

20. Sherina MS, Rampal L, Kaneson N. Psychological stress among undergraduate medical students. Med J Malaysia 2004;59(2):207-11.

21. Moffat KJ, McConnachie A, Ross S, Morrison JM. First year medical student stress and coping in a problem-based learning medical curriculum. Med Educ 2004;38(5):482-91.

22. Kohls NB, Bussing A, Sauer S, Riess J, Ulrich C, Vetter A. Psychological distress in medical students - a comparison of the Universities of Munich and Witten/Herdecke. Z Psychosom Med Psychother. 2012;58:409-16.

23. Meressa K, Mossie A, Gelaw Y. Effect of substance abuse on academic achievement of health officer and medical students 
of Jimma University, Southwest Ethiopia. Ethiop J Health Sci. 2009; 19(3):155-63.

24. Jagnany VK, Murarka S, Haider S, Kashyap V, Jagnany AK, Singh SB, et al. Pattern of substance abuse among the undergraduate medical students in a medical college hostel. Health Popul Perspect. 2008;31(3):212-9.

25. Kumari R, Nath B. Study on the use of tobacco among male medical students in Lucknow, India. Indian J Community Med. 2008;33(2):100-3.

26. Yusoff MSB. A confirmatory factor analysis study on the Medical Student Stressor Questionnaire among Malaysian medical students. Educ Med J. 2011;3(1):44-53.

27. Abdulghani HM, AlKanhal AA, Mahmoud ES, Ponnamperuma GG, Alfaris EA. Stress and Its Effects on Medical Students: A Crosssectional Study at a College of Medicine in Saudi Arabia. J Health, Popul Nutr. 2011;29(5):516-38.

28. Panchu P, Bahuleyan B, Vijayan V. An analysis of the factors leading to stress in Indian medical students. Int J Clin Exp Physiol. 2017;4(11):48-50.

29. Iqbal S, Gupta S, Venkatarao E. Stress, anxiety \& depression among medical undergraduate students \& their sociodemographic correlates. Indian J Med Res. 2005;141(3):354-7.

30. Anuradha R, Dutta R, Raja JD, Sivaprakasam P, Patil AB. Stress and stressors among medical undergraduate students: A cross-sectional study in a private medical college in Tamil Nadu. Indian J Community Med. 2017;42(4):222-5.

31. Bergmann C, Muth T, Loerbroks A. Medical students' perceptions of stress due to academic studies and its interrelationships with other domains of life: a qualitative study. Med Educ. 2019;24(1):1603526.

32. Chowdhury R, Mukherjee A, Mitra K, Naskar S, Karmakar PR, Lahiri SK et al. Perceived psychological stress among undergraduate medical students: Role of academic factors. Indian J Public Health. 2017;61(1):55-7.

33. Gupta S, Choudhury S, Das M, Mondol A, Pradhan R. Factors causing stress among students of a Medical College in Kolkata. India. Educ Health. 2015;28(1):92-5.

34. Sreedevi A, Rao GV, Bharath P, Reddy K, Parigala R, Pappu S et al. Study on stress among first-year medical students of
Kurnool Medical College, Kurnool. Int J Med Sci Public Health. 2016;5(5):852-5.

35. Neimi PM, Vainiomaki PT. Medical students' distress- quality, continuity and gender differences during a six year medical programme. Med Teach. 2006;28(2):136-41.

36. Dyrbye L, Thomas MR, Shanafelt TD. Medical student distress: causes, consequences and proposed solutions. Myo Clin Proc. 2005;80(12):1623-32.

37. Padhy GK, Das S, Sahu T, Parida S. Prevalence and Causes of Substance Abuse Among Undergraduate Medical College Students. Indian Med Gazette 2014;8;276-82.

38. ZulfikarAli RV, Vankar GK. Psychoactive substance use among medical students. Indian J Psychiat.1994;36(3):138-40.

39. Babalola EO, Akinhanmi A, Ogunwale A. Who guards the guards: Drug use pattern among medical students in a Nigerian University. Ann Med Health Sci Res. 2014;4(3):397-403.

40. Kumar S, Niranjan A, Kumar M. Pattern of substance abuse among undergraduate medical students in Central India: a cross sectional institutional study. Int J Health Sci Res. 2016;6(1):43-8.

41. Inderjit MG, Karibasappa GN, Nagesh L. Tobacco and alcohol use among male dental and medical students studying inDavangere city: A cross-sectional survey. J Dent Res Rev. 2015;2(4):156-60.

42. Verma R, Balhara YS, Dhawan A. Inhalant abuse: An exploratory study. Ind Psychiatry J. 2011;20(2):103-6.

43. Papazisis G, Tsakiridis I, Koulas I, Siafis S, Dagklis T, Kouvelas D et al. Prevalence of illicit drug use among medical students in Northern Greece and association with smoking and alcohol use. Hippokratia. 2017;21(1):13-8.

44. Garcia OL, Pereira BL, Arantes WG, Carvalho PJ, André M, Andrade SV et al. Drug consumption among medical students in São Paulo, Brazil: influences of gender and academic year. Rev Bras Psiquiatr. 2009;31(3):227-39.

How to cite this article: Hiremath SB, Chaitra VHM, Desai M. Stress and substance use among undergraduate medical students in a Government medical college in Northern Karnataka. Telangana J Psychiatry. 2020;6(2):119-124. 